\title{
A Pilot Plant Study on the Autoclaving of Food Wastes for Resource Recovery and Reutilization
}

\author{
Chia-Chi Chang ${ }^{1}$, Yen-Hau Chen ${ }^{1}$, Yi-Shiou Lin ${ }^{1}$, Zang-Sei Hung ${ }^{1}$, Min-Hao Yuan ${ }^{2}$, \\ Ching-Yuan Chang ${ }^{1,3, *}$, Yuan-Shen Li ${ }^{4}$, Je-Lueng Shie ${ }^{4} \oplus$, Yi-Hung Chen ${ }^{5}$, Yen-Chi Wang ${ }^{1}$, \\ Chun-Han $\mathrm{Ko}^{6}{ }^{6}$, Far-Ching Lin ${ }^{6}$, Chungfang $\mathrm{Ho}^{7}{ }^{,}$Bo-Liang Liu ${ }^{1}$, Kuang-Wei Liu ${ }^{8}$ and \\ Shi-Guan Wang ${ }^{8}$
}

1 Graduate Institute of Environmental Engineering, National Taiwan University, Taipei 106, Taiwan; d92541005@ntu.edu.tw (C.-C.C.); p29681726@gmail.com (Y.-H.C.); r98541133@ntu.edu.tw (Y.-S.L.); p94541203@ntu.edu.tw (Z.-S.H.); r98541128@ntu.edu.tw (Y.-C.W.); r04541129@ntu.edu.tw (B.-L.L.)

2 Department of Occupational Safety and Health, China Medical University, Taichung 404, Taiwan; mhyuan@mail.cmu.edu.tw

3 Department of Chemical Engineering, National Taiwan University, Taipei 106, Taiwan

4 Department of Environmental Engineering, National I-Lan University, Yi-Lan 260, Taiwan; ysli@niu.edu.tw (Y.-S.L.); jlshie@niu.edu.tw (J.-L.S.)

5 Department of Chemical Engineering and Biotechnology, National Taipei University of Technology, Taipei 106, Taiwan; yhchen1@ntut.edu.tw

6 School of Forestry and Resource Conservation, National Taiwan University, Taipei 106, Taiwan; chunhank@ntu.edu.tw (C.-H.K.); farching@ntu.edu.tw (F.-C.L.)

7 Department of International Business, Chung Yuan Christian University, Chung-Li 320, Taiwan; chungfangho@gmail.com

8 Environmental Analysis Laboratory, Environmental Protection Administration, Chung-Li 320, Taiwan; kwliu@mail.niea.gov.tw (K.-W.L.); skwang@mail.niea.gov.tw (S.-G.W.)

* Correspondence: cychang3@ntu.edu.tw; Tel.: +886-2-23638994

Received: 3 September 2018; Accepted: 1 October 2018; Published: 6 October 2018

Abstract: Autoclaving of food wastes (FW) for the resource recovery and reutilization was studied using the pilot plant scale. Experiments were conducted at various temperatures of 408, 428, and $438 \mathrm{~K}$ and times of 15 and $60 \mathrm{~min}$. The in-filled steam to the autoclave was supplied by the incineration plant with a gauge pressure of $7 \mathrm{~kg} / \mathrm{cm}^{2}$ and a temperature of $443 \mathrm{~K}$ or above. The results obtained from the experiments show that the less energy- and time-consuming autoclaving conditions ( $408 \mathrm{~K}$ and $15 \mathrm{~min}$, denoted as Case A408-15) are effective. Comparisons of the properties and characteristics of autoclaved FW $\left(\mathrm{FW}_{\mathrm{A}}\right)$ of Case A408-15 with those of FW are made. The wet bulk volume and wet bulk density of $\mathrm{FW}_{\mathrm{A}}$ are dramatically reduced to $15.64 \%$ and increased to $313.37 \%$ relative to those of FW, respectively. This makes the subsequent processing and reuse for $\mathrm{FW}_{\mathrm{A}}$ more convenient than FW. The autoclaving results in an increase of carbon content and a decrease of nitrogen content, and thus an increase of the $\mathrm{C} / \mathrm{N}$ ratio of $\mathrm{FW}_{\mathrm{A}}$. The contents of sulfur, hemi-cellulose, and cellulose of $\mathrm{FW}_{\mathrm{A}}$ are also reduced. All these fluctuations are beneficial for making compost or other usages from $\mathrm{FW}_{\mathrm{A}}$ than FW. The autoclaved liquid product (LA) separated from $\mathrm{FW}_{\mathrm{A}}$ and liquid condensate (LC) from the released gas possess high COD and TOC. These two liquids can be mixed for use as liquid fertilizers with proper conditioning. Alternatively, further anaerobic digestion of the mixture of $\mathrm{FW}_{\mathrm{A}}$, LA, and LC can offer enhanced biogas production for power generation. All these thus match the appeal of sustainable materials management and circular economy. The emitted gas from autoclaving contains no CO and some hydrocarbons. Suitable air pollution control is needed. The results and information obtained are useful for the proper recovery and reuse of abundant food wastes from domestic households and food industries. 
Keywords: autoclaving; food wastes; resource recovery; reutilization

\section{Introduction}

The autoclaving process is a mechanical heat treatment technique, which has been used to treat mixed industrial wastes, as well as municipal solid wastes (MSW), using saturated steam under high pressure. The autoclaving combined with the subsequent mechanical separation is known as mechanical heat treatment. The MSW, for example, were firstly autoclaved and hydrolyzed. Resource recycling takes advantage of the autoclaving process to reduce the volume of wastes and make them easy for sorting after solid-liquid separation. The valuable components of autoclaved solid products, such as the organic floc/fiber and inorganic recyclables (metal, plastics, and glass) can then be obtained separately from other in-organic discards or rejects [1-10]. In addition, the autoclaving pretreatment also sterilizes the wastes and decontaminates infectious and odor compounds, thereby enhancing the subsequent application of the recovered wastes. The floc/fiber can be used to manufacture (1) the refused derived fuel (RDF) or solid recovered fuel (SRF) via granulation with or without torrefaction [11,12], (2) the liquid fuel by hydrothermal liquefaction (HTL) [13], and (3) the compost [7]. The organic liquid can be handled by a wastewater treatment plant or recycled after detoxification and conditioning for fertilization application.

Autoclaving of bio-wastes can easily obtain solid organic floc/fiber without sorting the solid products, which contain little in-organics, if any; thus, they are better than those from autoclaving of mixed wastes such as MSW and are more appropriate for use as RDF, SRF, or compost. After heating the wastes with steam at proper detention time, this process can decompose the structure of the bio-wastes that are composed mostly of lignocellulose and enhance the efficiency of hydrolysis. Steam at high pressure will hydrolyze hemi-cellulose and cellulose, leading to lower density of cellulose crystal region while to higher porosity. The autoclaving helps to increase the carbon content and the carbon/nitrogen $(\mathrm{C} / \mathrm{N})$ ratio. Consequently, autoclaving pretreatment is promising to acquire better-quality organic floc/fiber for compost or other usages from a wide range of bio-wastes with a need to improve their $\mathrm{C} / \mathrm{N}$ ratio, such as cooked and raw food wastes (FW), agricultural and livestock farming wastes, etc.

In the bio-wastes, FW from domestic households and food industries are abundant, while FW is defined by Food and Agriculture Organization as food appropriate for human consumption that is discarded. Previous studies estimated that FW comprises $40 \%-85 \%$ of the MSWs in developing countries, while it accounts for $6 \%-30 \%$ of the MSWs in developed countries [14]. In Taiwan, although about $60.22 \%$ of total 7,870,896 ton MSW in 2017 was recycled and reutilized, indicating the significant achievement of MSW management, a lot of FW are not recycled but go through wasted garbage. The un-recycled and un-reused MSW consists of $36.12 \%$ paper, $4.63 \%$ textiles, $1.55 \%$ garden trimmings, $38.14 \% \mathrm{FW}, 16.00 \%$ plastics, $0.43 \%$ leather and rubber, $0.64 \%$ other combustibles (combustibles subtotal of $97.52 \%$, on dry base), $0.21 \%$ iron, $0.28 \%$ non-iron metals, $0.80 \%$ glasses, and $1.19 \%$ debris (incombustibles subtotal of $2.48 \%$, on dry base) [15]. Among them, FW must be handled properly due to their distinct properties. Some FW have been used for making compost via traditional composting method; however, most have been treated by incineration, and some by sanitary landfill. High carbohydrate content of FW often possesses high water content, which lowers their wet-basis heating value $\left(\mathrm{H}_{\mathrm{HWM}}\right)$ [16]. On the other hand, higher fixed carbon contents result in a higher heating value. In general, water content of FW could be $50 \%-80 \%$ depending on their composition and types of cuisine [14]. FW with high water content would be inadvisable for the treatment of incineration or landfill. The acidic leachate resulting from FW may hinder the operation of landfill, while the low $\mathrm{H}_{\mathrm{HWM}}$ of $\mathrm{FW}$ has low economic efficiency for combustion in incinerators. Although anaerobic digestion has been also applied for treating FW, improvement of the efficiency of biogas production for energy use and subsequent handling or treatment of waste sludge is needed. Moreover, 
traditional composting is time consuming. This work thus applied the autoclaving method to treat FW, aiming at resource recovery of organic floc/fiber and liquid products for better reutilization. A pilot plant experiment was conducted to demonstrate the systematic performance of autoclaving of FW. The obtained data will be beneficial for the design and cost-effectiveness assessment of the recovery and reuse of abundant food wastes from domestic households and food industries.

\section{Materials and Methods}

\subsection{Materials and Experiments}

The raw materials consisted of FW composed of un-cooked raw vegetables and leafy and fruit wastes collected from a fruit and vegetable market in Yi-Lan, Taiwan. The FW was autoclaved in a pilot-scale rotary batch reactor $(530 \mathrm{~L})$ with $1 \mathrm{hp}$ driving motor power. The autoclaving system is shown in Figure 1, which was manufactured by Chin Ying Fa Mechanical Ind. Co., Ltd. (Chang-Hua, Taiwan) and set up in Letzer Incineration Plant in Yi-Lan, Taiwan. The size of reactor is $680 \mathrm{~mm}$ in diameter and $1220 \mathrm{~mm}$ in length. The in-filled steam with the gauge pressure of $7 \mathrm{~kg} / \mathrm{cm}^{2}$ and temperature of above $443 \mathrm{~K}$ was supplied by the incineration plant. Operational conditions of autoclave were set at different temperatures $(\mathrm{T})(408,428$, and $438 \mathrm{~K})$ and times $(\mathrm{t})(15,60 \mathrm{~min})$ while being maintained at the same rotation speed $\mathrm{r}(7 \mathrm{rpm})$. The actual steam pressures $(\mathrm{P})$ for autoclaving at 408,428 , and $438 \mathrm{~K}$ were adjusted at 3,6 , and $7 \mathrm{~kg} / \mathrm{cm}^{2}$ gauge, respectively, which kept the temperatures at the corresponding setting values. $45.90 \mathrm{~kg}$ sample was charged per batch operation. The autoclaving was stopped at the end of setting time.

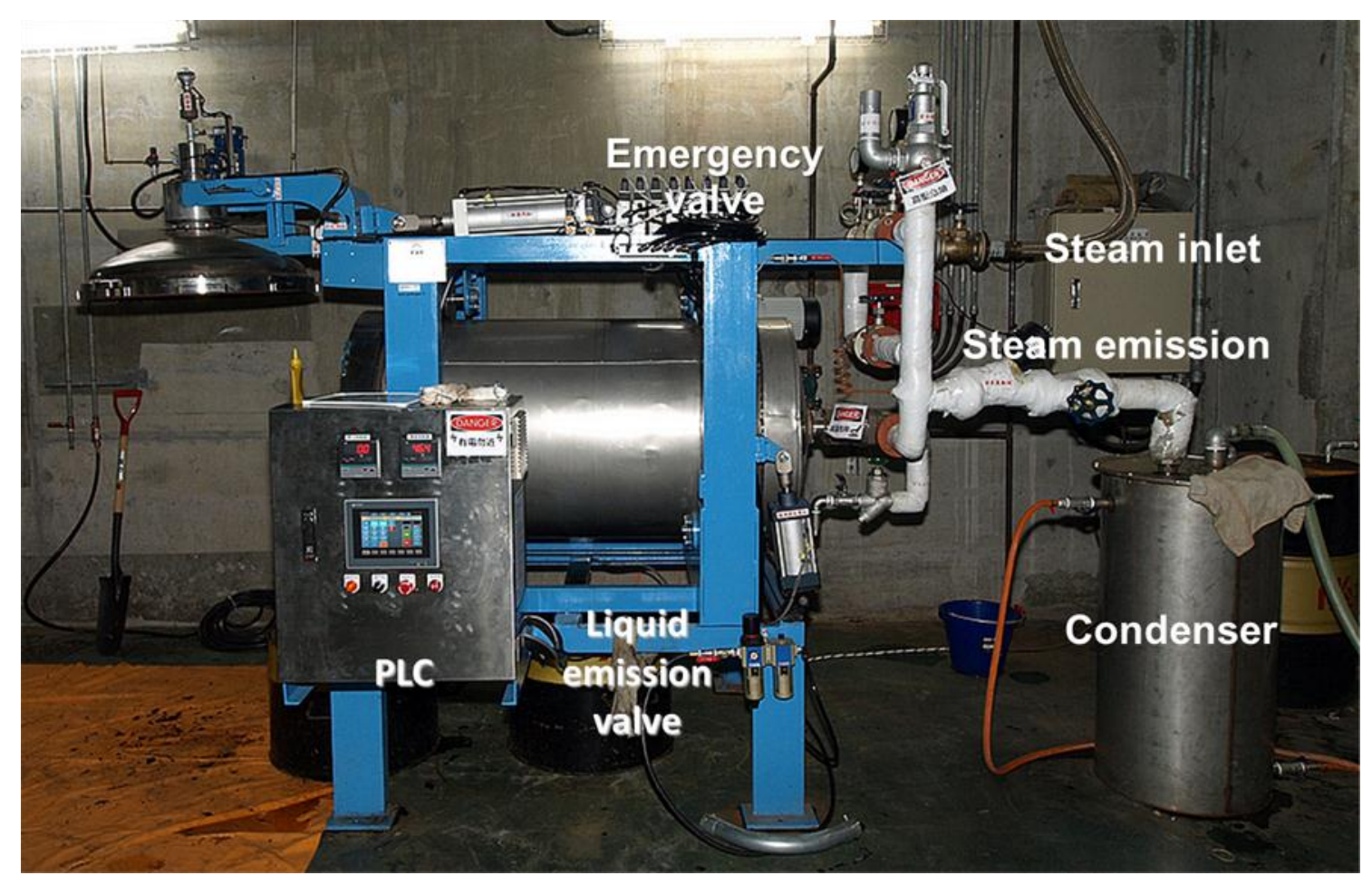

Figure 1. Diagram of autoclaving system.

The pressure in autoclave after finishing the autoclaving operation was then gradually reduced by releasing the gas. It was passed through a condenser to collect the condensed liquid product (LC) before discharging. The discharged (emitted) gases from relief valve after condenser were sampled as the pressures in autoclave were reduced to P1 and P2, for example, as P1 $=1.9-2.1 \mathrm{~kg} / \mathrm{cm}^{2}$ and P2 $=1.0-1.1 \mathrm{~kg} / \mathrm{cm}^{2}$ for cases A408-15 and A408-60, denoted as G1 and G2 gases, respectively. As the pressure in autoclave was reduced to ambient, the lid of autoclave was then opened. The gas sample 
in the autoclave after opening the reactor lid was also collected and noted as GR gas. The products in autoclave for autoclaving of FW were subjected to solid-liquid separation to obtain the solid product of autoclaved $\mathrm{FW}\left(\mathrm{FW}_{\mathrm{A}}\right)$ and the autoclaved liquid product (LA).

The properties of these solid and liquid products, as well gases produced, were then analyzed. The concentrations of gases sampled at P1, P2 and in the autoclave were denoted CG1, CG2, and CGR, respectively. Multiplication of $\mathrm{T}$ and $\mathrm{t}$, i.e., $\mathrm{T}-\mathrm{t}$, which is proportional to the energy consumed, was adapted as a parameter to elucidate the performance at various $\mathrm{T}-\mathrm{t}$ values.

\subsection{Analyses}

\subsubsection{Solid Analyses}

The basic analyses including proximate analysis, metal analysis, heating value analysis, and fiber analysis of bio-fiber (i.e., $\mathrm{FW}_{\mathrm{A}}$ ) were conducted in accordance with the standard methods from American Society for Testing and Materials (ASTM), National Institute of Environmental Analysis (NIEA), Chinese National Standards (CNS), and Taiwan Bureau of Standards, Metrology, and Inspection (TBSMI). The detailed descriptions of the methods of analyses and the instruments employed can be found in the study of Chen et al. [12].

\subsubsection{Liquid Analyses}

Chemical oxygen demand (COD), total organic carbons (TOC), and $\mathrm{pH}$ values were examined in accordance with the standard methods NIEA W517.52B, W530.51C, and W424.52A from National Institute of Environmental Analysis (NIEA) in Taiwan.

\subsubsection{Gas Analyses}

As for identifying organic component of gas products from autoclaving, gas chromatography mass spectrophotometer also called GC-MS (Thermo Scientific FOCUS GC Gas Chromatograph 1255080, Thermo Fisher Scientific Inc., Waltham, MA, USA) was used, adapting column Trace TR-1701 with $30 \mathrm{~m}$ length, $0.25 \mathrm{~mm}$ ID, and $0.25 \mu \mathrm{m}$ film thickness (Thermo Fisher Scientific Inc., Waltham, MA, USA). Helium was used as carrier gas in this system.

\section{Results and Discussion}

\subsection{Properties of $F W$}

On account of incoherent composition of FW, autoclaving was applied in this study to treat FW to seek the possibility for better utilizing the $\mathrm{FW}_{\mathrm{A}}$. The properties of raw FW are shown in Table 1 . The FW are wet, containing about $92.73 \mathrm{wt} . \%$ water. Its wet bulk density $\left(\rho_{\mathrm{BW}}\right)$ is $359 \mathrm{~kg} / \mathrm{m}^{3}$. With regard to dry basis, FW have high content of cellulose (47.96 wt.\%), indicating that leafy vegetables are the primary raw materials in FW [17]. The higher heating value per mass in dry basis $\left(\mathrm{H}_{\mathrm{HDM}}\right)$ of FW is $3954.66 \mathrm{kcal} / \mathrm{kg}$, while high water content in FW causes the higher heating value per mass in wet basis $\left(\mathrm{H}_{\mathrm{HWM}}\right)$ equivalent to only $287.45 \mathrm{kcal} / \mathrm{kg}$. According to the buying standard of wood pellet of IWPB (Initiative Wood Pellet Buyers) [18], the qualified $\mathrm{H}_{\mathrm{HWM}}$ of fuel should be above $3940.2 \mathrm{kcal} / \mathrm{kg}$, but that of FW is far less than this standard. Thus, treatment of FW, such as dewatering and torrefaction, is needed in order to increase its heating value of $\mathrm{H}_{\mathrm{HWM}}$. 
Table 1. Properties of raw food wastes $(\mathrm{FW})$ and autoclaved $\mathrm{FW}\left(\mathrm{FW}_{\mathrm{A}}\right)$ at various autoclaving temperatures $(\mathrm{T}, \mathrm{K})$ and times $(\mathrm{t}$, min).

\begin{tabular}{|c|c|c|c|c|c|c|c|c|}
\hline & & FW & $\mathrm{A} 408-15^{\mathrm{c}}$ & A408-60 & A428-15 & A428-60 & A438-15 & A438-60 \\
\hline \multirow{5}{*}{$\begin{array}{c}\text { Proximate } \\
\text { analysis a (wt.\%) }\end{array}$} & Combustibles, $\mathrm{M}_{\mathrm{C}}$ & 6.4347 & 9.1280 & 6.3803 & 8.3441 & 7.8499 & 7.9829 & 7.1092 \\
\hline & Fixed carbon, $\mathrm{M}_{\mathrm{FC}}$ & 0.1708 & 0.1871 & 0.2244 & 0.2531 & 0.2604 & 0.2569 & 0.2220 \\
\hline & Volatile matters, $\mathrm{M}_{\mathrm{VM}}$ & 6.2639 & 8.9409 & 6.1559 & 8.0910 & 7.5895 & 7.7260 & 6.8872 \\
\hline & Ash, $\mathrm{M}_{\mathrm{A}}$ & 0.8339 & 0.9056 & 0.8409 & 0.8668 & 1.0020 & 1.0351 & 0.9491 \\
\hline & Water content, $\mathrm{M}_{\mathrm{W}}$ & 92.7314 & 89.9664 & 92.7788 & 90.7891 & 91.1481 & 90.9820 & 91.9417 \\
\hline \multirow{5}{*}{$\begin{array}{c}\text { Ultimate } \\
\text { analysis }{ }^{b}(w t . \%)\end{array}$} & $\mathrm{C}$ & $37.545 \pm 0.136$ & $39.917 \pm 0.115$ & $39.202 \pm 0.066$ & $39.887 \pm 0.047$ & $40.626 \pm 0.085$ & $36.936 \pm 0.261$ & $42.021 \pm 0.748$ \\
\hline & $\mathrm{H}$ & $5.688 \pm 0.086$ & $5.903 \pm 0.064$ & $5.753 \pm 0.056$ & $5.863 \pm 0.051$ & $5.786 \pm 0.001$ & $5.635 \pm 0.081$ & $5.799 \pm 0.081$ \\
\hline & $\mathrm{O}$ & 51.582 & 50.059 & 50.917 & 50.477 & 49.678 & 53.436 & 48.416 \\
\hline & $\mathrm{N}$ & $3.514 \pm 0.013$ & $3.236 \pm 0.029$ & $3.283 \pm 0.030$ & $3.049 \pm 0.083$ & $3.103 \pm 0.116$ & $3.152 \pm 0.033$ & $3.024 \pm 0.004$ \\
\hline & $\mathrm{S}$ & $1.673 \pm 0.158$ & $0.887 \pm 0.056$ & $0.846 \pm 0.008$ & $0.725 \pm 0.037$ & $0.808 \pm 0.034$ & $0.816 \pm 0.040$ & $0.742 \pm 0.060$ \\
\hline \multirow{3}{*}{ Fiber analysis ${ }^{b}$} & Hemicellulose & 3.3881 & 0.9686 & 0.0473 & 0.0589 & 3.8682 & 0.7695 & 1.9842 \\
\hline & Cellulose & 47.9564 & 42.2591 & 40.6410 & 47.4245 & 44.1061 & 45.2092 & 38.7206 \\
\hline & Lignin & 22.9077 & 14.7414 & 16.0123 & 17.1644 & 26.1972 & 16.2790 & 24.2762 \\
\hline \multirow{3}{*}{ Heating value } & $\mathrm{H}_{\mathrm{HDM}}(\mathrm{kcal} / \mathrm{kg})$ & $3954.66 \pm 8.09$ & $3761.81 \pm 954.58$ & $3351.37 \pm 61.37$ & $3449.80 \pm 200.53$ & $2976.66 \pm 436.98$ & $3065.04 \pm 367.58$ & $2800.27 \pm 158.48$ \\
\hline & $\mathrm{H}_{\mathrm{HDV}}\left(\mathrm{kcal} / \mathrm{m}^{3}\right)$ & 103194.33 & 424625.63 & 272987.43 & 352711.78 & 304895.82 & 284973.23 & 233261.01 \\
\hline & $\mathrm{H}_{\mathrm{HWM}}(\mathrm{kcal} / \mathrm{kg})$ & 287.45 & 377.45 & 242.01 & 317.76 & 263.49 & 276.40 & 225.65 \\
\hline
\end{tabular}

${ }^{a}$ Wet basis. ${ }^{b}$ Dry basis. ${ }^{c}$ AT-t: Autoclaved at T K and t min. 


\subsection{Autoclaving of FW}

\subsubsection{Volume Reduction of $\mathrm{FW}_{\mathrm{A}}$}

Autoclaving has an enormous effect on volume reduction. Originally, the wet bulk volumes of input wet samples were all set at about $127.86 \mathrm{~L}$. After autoclaving at different temperatures and retention times, the wet bulk volumes of output wet products were all shrunken to 17.5-22.20 L $(13.69 \%-17.36 \%$ relative to that of FW), as shown in Figure 2. The weight of wet FW also reduced because of the thermal decomposition of FW during autoclaving, decreasing to around 18.09-22.56 kg from $45.90 \mathrm{~kg}$ at these conditions. The dry weight dropped from $3.34 \mathrm{~kg}$ to about $1.46-2.26 \mathrm{~kg}$. With the data of wet bulk volume and dry weight, the indicator "wet bulk density" can be computed to demonstrate more clearly the efficiency of autoclaving on volume reduction.

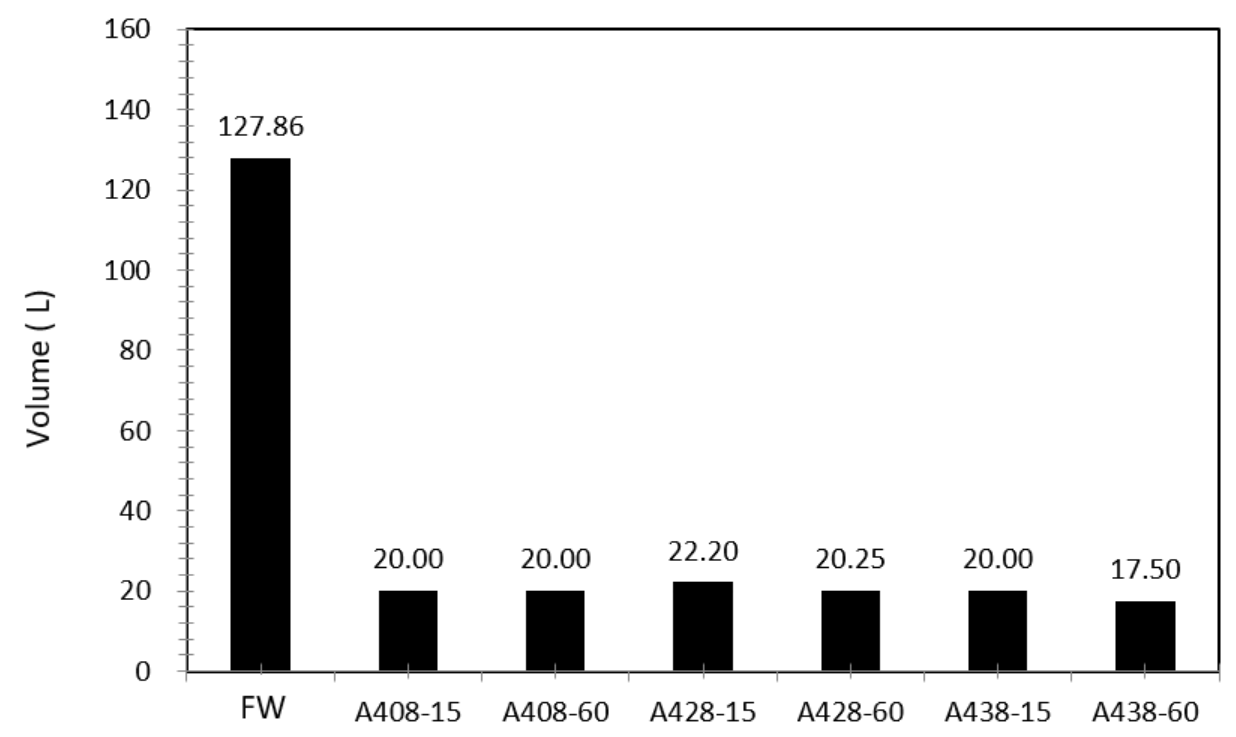

Figure 2. Change of wet bulk volume $\left(\mathrm{V}_{\mathrm{BW}}\right)$ of food wastes $(\mathrm{FW})$ after autoclaving.

Figure 3 indicates that the wet bulk density $\left(\rho_{\mathrm{BW}}\right.$ ) of $\mathrm{FW}$ increases drastically from $359 \mathrm{~kg} / \mathrm{m}^{3}$ to $1125 \mathrm{~kg} / \mathrm{m}^{3}$ after autoclaving at conditions of $408 \mathrm{~K}$ and $15 \mathrm{~min}$ (Case A408-15). The conditions of a higher temperature and longer retention time did not enhance the $\rho_{\mathrm{BW}}$ to a higher value, while $\rho_{\mathrm{BW}}$ was about $1031-1157 \mathrm{~kg} / \mathrm{m}^{3}(287.19 \%-322.28 \%$ relative to that of $\mathrm{FW})$.

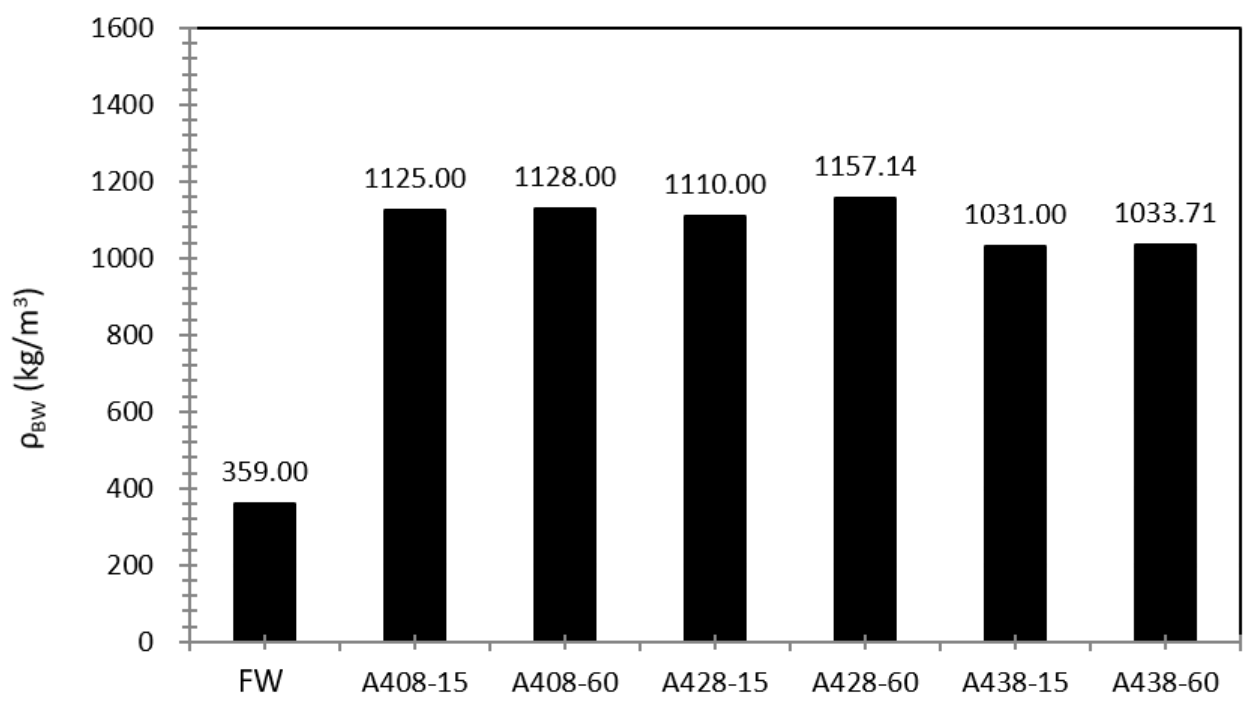

Figure 3. Change of wet bulk density $\left(\rho_{\mathrm{BW}}\right)$ of FW after autoclaving. 
At the most energetic situation examined with $438 \mathrm{~K}$ and $60 \mathrm{~min}$, the $\rho_{\mathrm{BW}}$ approaches $1034 \mathrm{~kg} / \mathrm{m}^{3}$, which is lower than that of Case A408-15. By autoclaving performed in this research, the FW could be more concentrated, and the conditions of $408 \mathrm{~K}$ and $15 \mathrm{~min}$ are recommended in order to decrease energy consumption while achieving efficient volume reduction. Notice that the dry bulk density $\left(\rho_{\mathrm{BD}}\right)$ of $\mathrm{FW}$ also increases from $26.09 \mathrm{~kg} / \mathrm{m}^{3}$ to $81.45-112.88 \mathrm{~kg} / \mathrm{m}^{3}$. Thus, autoclaving process shows significantly pronounced effect on volume reduction and increase of mass intensity (mass per volume) of $\mathrm{FW}_{\mathrm{A}}$.

\subsubsection{Change of Some Basic Properties of $\mathrm{FW}_{\mathrm{A}}$}

Some basic properties of FW after autoclaving are presented in Table 1. The results indicated slight change of the properties of proximate analysis of $\mathrm{FW}_{\mathrm{A}}$ in comparison with those of the raw FW. Water contents of $\mathrm{FW}_{\mathrm{A}}$ remained high at around 89.97-92.78 wt.\% among our experimental conditions. The high water-content may lead to a need for dehydration of $\mathrm{FW}_{\mathrm{A}}$ for subsequent applications such as making solid fuel, which requires additional energy input. Fiber analysis showed that after autoclaving, the contents of hemi-cellulose, cellulose, and lignin generally decrease, except those for cases A428-60 and A438-60. This demonstrates that the construction of lignocellulose was destroyed during the heat treatment. Moreover, sulfur content of FW decreased remarkably after autoclaving. This may be attributed to the dissolution of sulfur compounds in liquid due to thermal reaction with steam. The sulfur content is reduced from $1.67 \mathrm{wt} . \%$ to around $0.73-0.89 \mathrm{wt} . \%$, proving that autoclaving has ability to de-pollute the $\mathrm{FW}_{\mathrm{A}}$.

\subsubsection{Energy Intensity of $\mathrm{FW}_{\mathrm{A}}$}

The higher heating values per mass in dry basis $\left(\mathrm{H}_{\mathrm{HDM}}\right)$ of $\mathrm{FW}_{\mathrm{A}}$ were $2800.27-3761.81 \mathrm{kcal} / \mathrm{kg}$, which were lower than those of original FW of $3954.66 \mathrm{kcal} / \mathrm{kg}$. With higher temperature and longer retention time, $\mathrm{H}_{\mathrm{HDM}}$ was decreased to the lowest value of $2800.27 \mathrm{kcal} / \mathrm{kg}$ at operation conditions of $438 \mathrm{~K}$ and $60 \mathrm{~min}$. This was due to tense hydrolysis and oxidation of organic compounds in FW by autoclaving. As high water-content is still exhibited in all conditions of $\mathrm{FW}_{\mathrm{A}}$, the $\mathrm{H}_{\mathrm{HWM}}$ of $\mathrm{FW}_{\mathrm{A}}$ listed in Table 1 was as low as $225.65-377.45 \mathrm{kcal} / \mathrm{kg}$. This would be a barrier for applying $\mathrm{FW}_{\mathrm{A}}$ as a solid fuel. It is still worth noticing that evident volume reduction by autoclaving did raise the volume energy intensity of $\mathrm{FW}_{\mathrm{A}}$, although the decrease of $\mathrm{H}_{\mathrm{HDM}}$ and the low $\mathrm{H}_{\mathrm{HWM}}$ could not be avoided.

Regarding Table 1 , the higher heating value per volume in dry basis $\left(\mathrm{H}_{\mathrm{HDV}}\right)$ of $\mathrm{FW}_{\mathrm{A}}$ reaches the highest value of $424,626 \mathrm{kcal} / \mathrm{m}^{3}$ at the conditions of $408 \mathrm{~K}$ and $15 \mathrm{~min}$ from the original value of $103,194 \mathrm{kcal} / \mathrm{m}^{3}$. With increasing retention time and increasing temperature, the $\mathrm{H}_{\mathrm{HDV}}$ generally decreases due to the loss of hemi-cellulose, cellulose, and lignin, as noticed previously, and is much more easily decomposed in relatively high energetic environments. Hemi-cellulose, cellulose, and lignin are composed of organic compounds with high content of carbon and hydrogen, which have high heating values. As a result, loss of them results in decrease of energy intensity. From the prospect of recovery and reutilization of FW by autoclaving pretreatment, the findings suggest that mild operation temperature and short operation time (such as $408 \mathrm{~K}$ and $15 \mathrm{~min}$ ) can conserve substantial energy needed in autoclaving of raw materials and effectively reduce the volume.

\subsubsection{Comparison of Properties of $\mathrm{FW}_{\mathrm{A}}$ with Compost Standards}

The qualities of $\mathrm{FW}_{\mathrm{A}}$, along with those of $\mathrm{FW}$, are compared with the standards for compost as listed in Table 2 to establish the possibility for utilizing $\mathrm{FW}_{\mathrm{A}}$ as compost. Basically, $\mathrm{FW}_{\mathrm{A}}$ obtained at different conditions have uniform heavy metal compositions. The water contents of $\mathrm{FW}_{\mathrm{A}}$ of $89.97-92.78 \mathrm{wt} . \%$ exceed the standard of $40 \mathrm{wt} . \%$. The contents of $\mathrm{P}_{2} \mathrm{O}_{5}$ of $8.82 \times 10^{-3}$ to $1.32 \times 10^{-2}$ wt. $\%$ and $\mathrm{K}_{2} \mathrm{O}$ of $1.92 \times 10^{-2}$ to $2.40 \times 10^{-2}$ wt. $\%$ of $\mathrm{FW}_{\mathrm{A}}$ in wet basis are lower than the regulated values of $0.3-6.0 \mathrm{wt} . \%$ and $0.3-4.0 \mathrm{wt} . \%$, respectively. However, contents of the heavy metals in $\mathrm{FW}_{\mathrm{A}}$ all are very low and meet the appropriate standards. The $\mathrm{C} / \mathrm{N}$ ratios of $\mathrm{FW}_{\mathrm{A}}$ are around 11.72 to $13.9 \mathrm{wt} . \% / \mathrm{wt} . \%$, which are not only higher than those of FW of $10.68 \mathrm{wt} . \% / \mathrm{wt} . \%$ but also fit the 
standard restricted from 10 to $20 \mathrm{wt} . \% / \mathrm{wt} . \%$ in wet basis. By adjusting the water content, nutrition, and $\mathrm{C} / \mathrm{N}$ ratio properly, one can produce compost via rapid curing from $\mathrm{FW}_{\mathrm{A}}$. The $\mathrm{FW}_{\mathrm{A}}$ obtained from autoclaving are more beneficial than raw FW with (1) higher wet bulk density requiring smaller reactor or working space and (2) shorter curing time for making the compost product, because $\mathrm{FW}_{\mathrm{A}}$ was already significantly decomposed by autoclaving. Again, as a result of no significant distinction of composition of products obtained from the various conditions employed in this study, A408-15 at $408 \mathrm{~K}$ with $15 \mathrm{~min}$ would be the proper condition for autoclaving of FW with less energy consumption.

\subsubsection{Properties of Autoclaved and Condensed Liquid Products}

Table 3 presents the properties of autoclaved liquid product (LA) separated from $\mathrm{FW}_{\mathrm{A}}$ and of condensed liquid product (LC) from the released gas from autoclave. The electrical conductivity (EC), COD, TOC, and ammonium nitrogen $\left(\mathrm{NH}_{3}-\mathrm{N}\right)$ of LA are about $9.15 \times 10^{3}-9.86 \times 10^{3} \mu \mathrm{S} / \mathrm{cm}$, $1.04 \times 10^{4}-2.25 \times 10^{4} \mathrm{mg} / \mathrm{L}, 9.38 \times 10^{2}-1.21 \times 10^{3} \mathrm{mg} / \mathrm{L}$ and $2.70 \times 10^{2}-3.10 \times 10^{2} \mathrm{mg} / \mathrm{L}$, respectively. The corresponding values of $\mathrm{LC}$ are of $2.39 \times 10^{2}-2.77 \times 10^{2} \mu \mathrm{S} / \mathrm{cm}$, $3.06 \times 10^{2}-8.67 \times 10^{2} \mathrm{mg} / \mathrm{L}, 1.33 \times 10^{2}-2.79 \times 10^{2} \mathrm{mg} / \mathrm{L}$, and 3.0-3.5 mg/L, respectively, which are lower than those of LA. Thus, most of the ionic, oxygen consuming, organic, and nitrogen-containing matters, which are dissolved or extracted from FW, are retained in LA, although some of them are emitted with the steam while being re-collected by condensation. The low $\mathrm{pH}$ values of 4.42-5.18 of LA are attributed to the formation of organic acids by the hydrolysis of hemi-cellulose and cellulose in the biomass of FW during autoclaving. Consequently, this thus also resulted in high COD and TOC concentrations as anticipated. Released waste steam also carried out some organic compounds, for which the condensable were condensed in condenser bucket. The $\mathrm{pH}$ values of $\mathrm{LC}$ were around 7.26-8.78. The LA and LC can be mixed and used as liquid fertilizer by conditioning their properties, such as increasing the $\mathrm{pH}$ value with alkaline additives while lowering the $\mathrm{EC}$ by dilution. It is noticed that the limiting values of EC for irrigate water and rice plantation are 750 and $1250 \mu \mathrm{S} / \mathrm{cm}$, respectively, while $\mathrm{pH}$ value of irrigate water should be in 6.0-9.0 [19].

Moreover, all these COD and TOC are dissolved from the FW during autoclaving, indicating that the $\mathrm{FW}_{\mathrm{A}}$ are more biodegradable than FW. The enhancement effect of thermal pre-treatment on the activated sludge solubilisation and thus the anaerobic digestion biodegradability was also noted by Bougrier et al. [20]. In a recent study, Le et al. [21] has also demonstrated that the biodegradability and thus the biogas production from anaerobic digestion increased with sludge solubilisation. Thus, the LA and LC can be mixed with $\mathrm{FW}_{\mathrm{A}}$ as feed for anaerobic digestion to produce biogas for power generation.

\subsubsection{Properties of Gases Formed}

As described in Section 2.1 Materials and Experiments, three different gas samples, namely, G1, G2, and GR, were collected. The analyses of these gases included detection of total hydrocarbons (THCs) and identification of organic compounds. Figure 4 shows the concentrations of THCs of gases G1, G2, and GR, i.e., CG1, CG2, and CGR, at different autoclaving conditions. The concentrations at various conditions have no obvious tendency on account of the varied composition of different batches of FW. The emitted gas concentrations of CG1, CG2, and CGR are in the range of 143-3424 ppmv, 48-2424 ppmv, and 262-1407 ppmv, respectively. Among all the conditions, autoclaving at $408 \mathrm{~K}$ and $60 \mathrm{~min}$ has the highest THC concentrations of 3424, 2424, and 1407, respectively, for CG1, CG2, and CGR. 
Table 2. Comparison of properties of FW and $\mathrm{FW}_{\mathrm{A}}$ with compost standards.

\begin{tabular}{|c|c|c|c|c|c|c|c|c|}
\hline Property in Wet Basis & Standard & FW & A408-15 & A408-60 & A428-15 & A428-60 & A438-15 & A438-60 \\
\hline $\mathrm{H}_{2} \mathrm{O}(\mathrm{wt} . \%)$ & $<40$ & 92.7314 & 89.9664 & 92.7788 & 90.7891 & 91.1481 & 90.9820 & 91.9417 \\
\hline C/N (wt.\%/wt.\%) & $10-25$ & 10.68 & 12.34 & 11.94 & 13.08 & 13.09 & 11.72 & 13.90 \\
\hline $\mathrm{N} *($ wt. $\%)$ & $0.6-5.0$ & $3.514 \pm 0.013$ & $3.236 \pm 0.029$ & $3.283 \pm 0.030$ & $3.049 \pm 0.083$ & $3.103 \pm 0.116$ & $3.152 \pm 0.033$ & $3.024 \pm 0.004$ \\
\hline $\mathrm{P}(\mathrm{mg} / \mathrm{kg})$ & & $3.91 \times 10^{3}$ & $4.20 \times 10^{3}$ & $4.54 \times 10^{3}$ & $3.85 \times 10^{3}$ & $5.03 \times 10^{3}$ & $4.94 \times 10^{3}$ & $5.76 \times 10^{3}$ \\
\hline $\mathrm{P}_{2} \mathrm{O}_{5}$ (wt.\%) & $0.3-6.0$ & $8.96 \times 10^{-3}$ & $9.62 \times 10^{-3}$ & $1.04 \times 10^{-2}$ & $8.82 \times 10^{-3}$ & $1.15 \times 10^{-2}$ & $1.13 \times 10^{-2}$ & $1.32 \times 10^{-2}$ \\
\hline $\mathrm{K}(\mathrm{mg} / \mathrm{kg})$ & & $2.92 \times 10^{4}$ & $1.80 \times 10^{4}$ & $1.97 \times 10^{4}$ & $1.60 \times 10^{4}$ & $1.59 \times 10^{4}$ & $1.99 \times 10^{4}$ & $1.79 \times 10^{4}$ \\
\hline $\mathrm{K}_{2} \mathrm{O}($ wt. $\%)$ & $0.3-4.0$ & $3.52 \times 10^{-2}$ & $2.17 \times 10^{-2}$ & $2.37 \times 10^{-2}$ & $1.93 \times 10^{-2}$ & $1.92 \times 10^{-2}$ & $2.40 \times 10^{-2}$ & $2.16 \times 10^{-2}$ \\
\hline $\mathrm{Cu}(\mathrm{mg} / \mathrm{kg})$ & $<100$ & 42.4 & 31.7 & 30.5 & 29.8 & 52.5 & 56.5 & 50.9 \\
\hline $\mathrm{Cr}(\mathrm{mg} / \mathrm{kg})$ & $<150$ & 8.00 & 7.61 & 5.77 & 5.74 & 7.73 & 6.65 & 7.52 \\
\hline $\mathrm{Pb}(\mathrm{mg} / \mathrm{kg})$ & $<150$ & 5.84 & 5.89 & 6.74 & 7.16 & 9.86 & 5.44 & 11.1 \\
\hline $\mathrm{Cd}(\mathrm{mg} / \mathrm{kg})$ & $<2.0$ & $<0.70$ & $<0.70$ & $<0.70$ & $<0.70$ & $<0.70$ & $<0.70$ & $<0.70$ \\
\hline $\mathrm{Zn}(\mathrm{mg} / \mathrm{kg})$ & $<250$ & 41.3 & 75.7 & 94.0 & 77.2 & 139 & 79.0 & 369 \\
\hline $\mathrm{Ni}(\mathrm{mg} / \mathrm{kg})$ & $<25.0$ & 14.3 & 12.2 & 18.0 & 12.6 & 20.3 & 22.1 & 19.5 \\
\hline As $(\mathrm{mg} / \mathrm{kg})$ & $<25.0$ & $<1.7$ & $<1.7$ & $<1.7$ & $<1.7$ & $<1.7$ & $<1.7$ & ND \\
\hline $\mathrm{Hg}(\mathrm{mg} / \mathrm{kg})$ & $<1.0$ & $<0.015$ & $<0.015$ & 0.025 & $<0.015$ & 0.021 & 0.015 & $<0.015$ \\
\hline
\end{tabular}

* Dry basis.

Table 3. Properties of autoclaved and condensed liquid products obtained from autoclaving of FW.

\begin{tabular}{|c|c|c|c|c|c|c|c|}
\hline \multicolumn{8}{|c|}{ Autoclaved Liquid (LA) } \\
\hline \multicolumn{3}{|c|}{ Condition } & \multicolumn{5}{|c|}{ Item } \\
\hline Temperature (K) & Time (min) & Rotation Speed (rpm) & $\mathrm{pH}$ & Electrical Conductivity $(\mu \mathrm{S} / \mathrm{cm})$ & COD (mg/L) & TOC $(\mathrm{mg} / \mathrm{L})$ & $\mathrm{NH}_{3}-\mathrm{N}(\mathrm{mg} / \mathrm{L})$ \\
\hline 408 & 15 & 7 & 4.94 & $9.84 \times 10^{3}$ & $1.04 \times 10^{4}$ & $1.21 \times 10^{3}$ & $2.70 \times 10^{2}$ \\
\hline 408 & 60 & 7 & 4.73 & $9.15 \times 10^{3}$ & $2.00 \times 10^{4}$ & $9.38 \times 10^{2}$ & - \\
\hline 428 & 15 & 7 & 4.72 & $9.68 \times 10^{3}$ & $2.16 \times 10^{4}$ & $1.11 \times 10^{3}$ & $3.10 \times 10^{2}$ \\
\hline 428 & 60 & 7 & 4.44 & $9.17 \times 10^{3}$ & $1.96 \times 10^{4}$ & $9.48 \times 10^{2}$ & - \\
\hline 438 & 15 & 7 & 5.18 & $9.86 \times 10^{3}$ & $2.25 \times 10^{4}$ & $1.04 \times 10^{3}$ & - \\
\hline 438 & 60 & 7 & 4.42 & $9.20 \times 10^{3}$ & $2.12 \times 10^{4}$ & $9.70 \times 10^{2}$ & - \\
\hline \multicolumn{8}{|c|}{ Condensed Liquid (LC) } \\
\hline \multicolumn{3}{|c|}{ Condition } & \multicolumn{5}{|c|}{ Item } \\
\hline Temperature (K) & Time (min) & Rotation Speed (rpm) & $\mathrm{pH}$ & Electrical Conductivity $(\mu \mathrm{S} / \mathrm{cm})$ & COD $(\mathrm{mg} / \mathrm{L})$ & TOC (mg/L) & $\mathrm{NH}_{3}-\mathrm{N}(\mathrm{mg} / \mathrm{L})$ \\
\hline 408 & 15 & 7 & 7.26 & $2.67 \times 10^{2}$ & $3.06 \times 10^{2}$ & $1.33 \times 10^{2}$ & 3.00 \\
\hline 408 & 60 & 7 & 6.68 & $2.65 \times 10^{2}$ & $6.27 \times 10^{2}$ & $2.24 \times 10^{2}$ & - \\
\hline 428 & 15 & 7 & 8.54 & $2.48 \times 10^{2}$ & $3.90 \times 10^{2}$ & $1.51 \times 10^{2}$ & 3.50 \\
\hline 428 & 60 & 7 & 8.29 & $2.39 \times 10^{2}$ & $8.27 \times 10^{2}$ & $2.57 \times 10^{2}$ & - \\
\hline 438 & 15 & 7 & 8.78 & $2.77 \times 10^{2}$ & $5.07 \times 10^{2}$ & $1.87 \times 10^{2}$ & - \\
\hline 438 & 60 & 7 & 8.19 & $2.44 \times 10^{2}$ & $8.67 \times 10^{2}$ & $2.79 \times 10^{2}$ & - \\
\hline
\end{tabular}



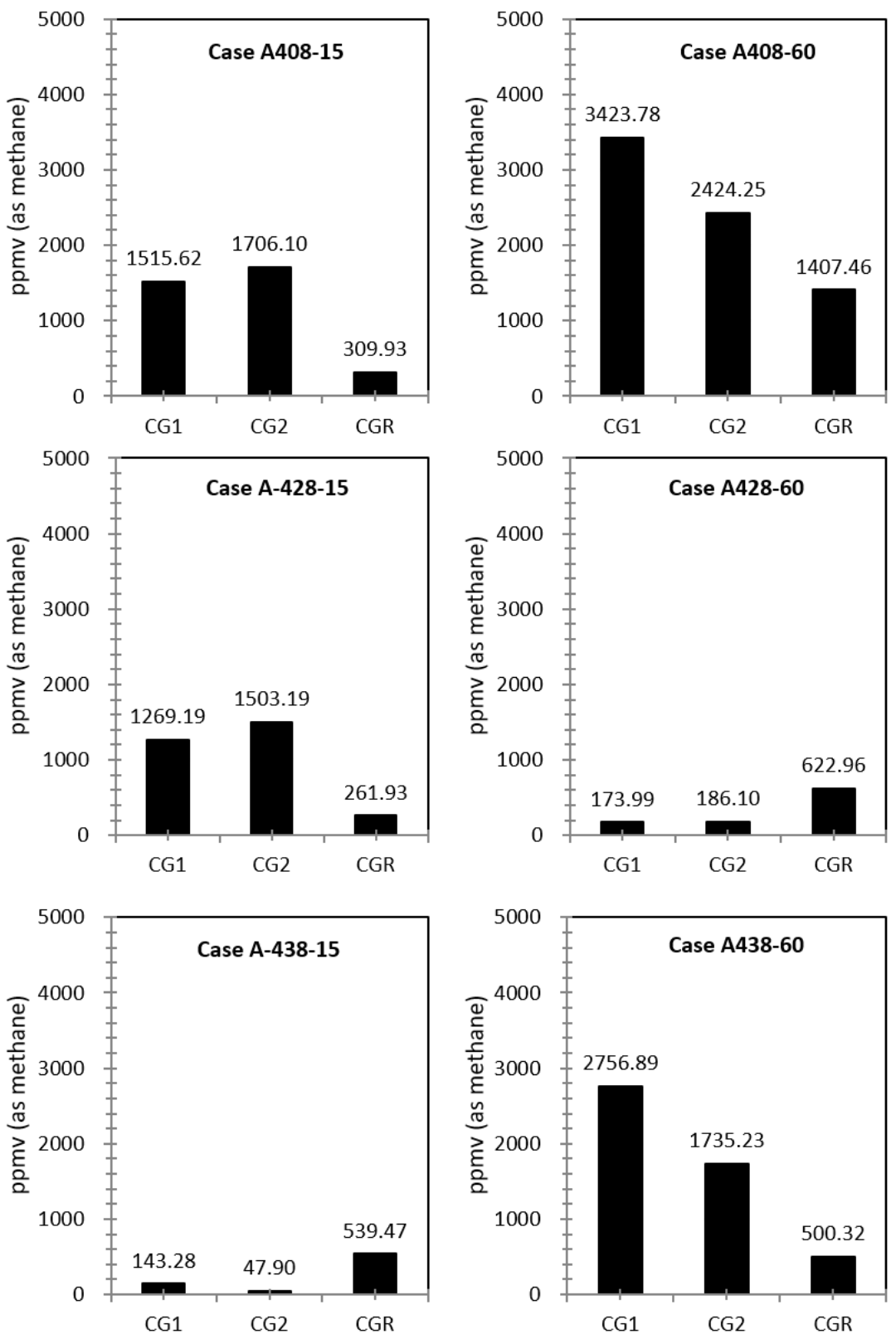

Figure 4. THCs of CG1, CG2, and CGR from autoclaving of FW. CG1 and CG2, and CGR: concentrations of released gases after condenser as pressures in autoclave were reduced to P1 and P2, and that of gas in autoclave after opening the reactor lid.

Table 4 elucidates the gas components in CG1, CG2, and CGR indicated by GC-MS. The THCs in CG1 and CG2 are mostly non-polar species, indicating that volatiles from FW were also pyrolyzed during autoclaving. This is consistent with the decreasing of dry weight of FW from $3.34 \mathrm{~kg}$ to about $1.46-2.26 \mathrm{~kg}$ after autoclaving, as pointed in previous section. Notice that GR was collected after the reactor lid was opened. Some components may be emitted to the ambient, thus resulting in fewer species in CGR, such as $\mathrm{C}_{10} \mathrm{H}_{16}$ being retained. There was no carbon monoxide formed, as autoclaving process was operated at oxygen-rich environment. Saturated steam also acted as an oxidant for decomposing the FW during autoclaving at high pressure; therefore, different aldehydes were produced. What should be noticed is that sulfur compounds were also formed from the sulfur-containing matters in FW during autoclaving. The sulfur element occupied $1.67 \mathrm{wt} . \%$ of FW in dry basis and was reduced to $0.725-0.887 \mathrm{wt} . \%$ after autoclaving, which led to the production of dimethyl sulfide, dimethyl disulfide, and other sulfides. 
Table 4. Gaseous hydrocarbon products from autoclaving of FW.

\begin{tabular}{|c|c|c|c|c|c|c|c|c|c|c|c|c|c|c|c|c|c|c|c|c|}
\hline \multicolumn{3}{|c|}{ Condition } & \multicolumn{3}{|c|}{$408 \mathrm{~K}, 15 \mathrm{~min}$} & \multicolumn{3}{|c|}{$408 \mathrm{~K}, 60 \mathrm{~min}$} & \multicolumn{3}{|c|}{$428 \mathrm{~K}, 15 \mathrm{~min}$} & \multicolumn{3}{|c|}{$428 \mathrm{~K}, 60 \mathrm{~min}$} & \multicolumn{3}{|c|}{$438 \mathrm{~K}, 15 \mathrm{~min}$} & \multicolumn{3}{|c|}{$438 \mathrm{~K}, 60 \mathrm{~min}$} \\
\hline \multicolumn{3}{|c|}{ Rotation Speed } & \multicolumn{3}{|c|}{$7 \mathrm{rpm}$} & \multicolumn{3}{|c|}{$7 \mathrm{rpm}$} & \multicolumn{3}{|c|}{$7 \mathrm{rpm}$} & \multicolumn{3}{|c|}{$7 \mathrm{rpm}$} & \multicolumn{3}{|c|}{$7 \mathrm{rpm}$} & \multicolumn{3}{|c|}{$7 \mathrm{rpm}$} \\
\hline Limonene & $\mathrm{C}_{10} \mathrm{H}_{16}$ & \multirow{5}{*}{ Alkene } & $\bullet^{1}$ & $\bullet^{2}$ & $\bullet^{3}$ & $\bullet^{1}$ & $\bullet^{2}$ & $\bullet^{3}$ & $\bullet^{1}$ & $\bullet^{2}$ & $0^{3}$ & $\bullet^{1}$ & $\bullet^{2}$ & $\bullet^{3}$ & $\bullet^{1}$ & $\bullet^{2}$ & $\bullet^{3}$ & $\bullet^{1}$ & $\bullet^{2}$ & $\bullet^{3}$ \\
\hline$\alpha$-pinene & $\mathrm{C}_{10} \mathrm{H}_{16}$ & & $\bullet$ & $\bullet$ & $\bullet$ & $\bullet$ & $\bullet$ & & $\bullet$ & $\bullet$ & $\bullet$ & & $\bullet$ & $\bullet$ & $\bullet$ & $\bullet$ & $\bullet$ & $\bullet$ & $\bullet$ & \\
\hline $1 \mathrm{R}-\alpha$-pinene & $\mathrm{C}_{10} \mathrm{H}_{16}$ & & & & & & & $\bullet$ & & & & & & & & & & & & $\bullet$ \\
\hline $1 \mathrm{~S}$ - $\alpha$-pinene & $\mathrm{C}_{10} \mathrm{H}_{16}$ & & & & & & & & & & & $\bullet$ & & & & & & & & \\
\hline$\beta$-pinene & $\mathrm{C}_{10} \mathrm{H}_{16}$ & & & & & & & $\bullet$ & & & & & & $\bullet$ & & & $\bullet$ & & & \\
\hline 2-methyl propanal & $\mathrm{C}_{4} \mathrm{H}_{8} \mathrm{O}$ & \multirow{3}{*}{ Aldehyde } & $\bullet$ & $\bullet$ & & $\bullet$ & $\bullet$ & & $\bullet$ & $\bullet$ & & $\bullet$ & $\bullet$ & & $\bullet$ & $\bullet$ & $\bullet$ & $\bullet$ & $\bullet$ & $\bullet$ \\
\hline 3-methyl butanal & $\mathrm{C}_{5} \mathrm{H}_{10} \mathrm{O}$ & & $\bullet$ & $\bullet$ & & $\bullet$ & $\bullet$ & & $\bullet$ & $\bullet$ & & $\bullet$ & $\bullet$ & & $\bullet$ & $\bullet$ & $\bullet$ & $\bullet$ & $\bullet$ & $\bullet$ \\
\hline 2-methyl butanal & $\mathrm{C}_{5} \mathrm{H}_{10} \mathrm{O}$ & & & & & & & & & & & $\bullet$ & $\bullet$ & & $\bullet$ & $\bullet$ & & $\bullet$ & $\bullet$ & \\
\hline Carbon dioxide & $\mathrm{CO}_{2}$ & \multirow{7}{*}{ Others } & & $\bullet$ & & $\bullet$ & & & $\bullet$ & $\bullet$ & & $\bullet$ & $\bullet$ & & $\bullet$ & $\bullet$ & & $\bullet$ & $\bullet$ & \\
\hline Alcohol & $\mathrm{C}_{2} \mathrm{H}_{6} \mathrm{O}$ & & & & & & & & & & & & & & & & $\bullet$ & & & $\bullet$ \\
\hline Dimethyl sulfide & $\mathrm{C}_{2} \mathrm{H}_{6} \mathrm{~S}$ & & $\bullet$ & $\bullet$ & & $\bullet$ & $\bullet$ & & $\bullet$ & $\bullet$ & & $\bullet$ & $\bullet$ & & $\bullet$ & $\bullet$ & & $\bullet$ & $\bullet$ & \\
\hline Dimethyl disulfide & $\mathrm{C}_{2} \mathrm{H}_{6} \mathrm{~S}_{2}$ & & $\bullet$ & $\bullet$ & & $\bullet$ & $\bullet$ & $\bullet$ & $\bullet$ & $\bullet$ & & $\bullet$ & $\bullet$ & $\bullet$ & $\bullet$ & & $\bullet$ & $\bullet$ & $\bullet$ & $\bullet$ \\
\hline 2,3-butanedione & $\mathrm{C}_{4} \mathrm{H}_{6} \mathrm{O}_{2}$ & & & & & & & & & & & & $\bullet$ & & & $\bullet$ & & & $\bullet$ & \\
\hline Nitrogen & $\mathrm{N}_{2}$ & & $\bullet$ & $\bullet$ & $\bullet$ & $\bullet$ & $\bullet$ & $\bullet$ & $\bullet$ & $\bullet$ & $\bullet$ & $\bullet$ & $\bullet$ & $\bullet$ & $\bullet$ & $\bullet$ & $\bullet$ & $\bullet$ & $\bullet$ & $\bullet$ \\
\hline Water & $\mathrm{H}_{2} \mathrm{O}$ & & $\bullet$ & $\bullet$ & $\bullet$ & $\bullet$ & $\bullet$ & $\bullet$ & $\bullet$ & $\bullet$ & $\bullet$ & $\bullet$ & $\bullet$ & $\bullet$ & $\bullet$ & $\bullet$ & $\bullet$ & $\bullet$ & $\bullet$ & $\bullet$ \\
\hline
\end{tabular}

1, 2: released gases of G1, G2 after condenser as pressures in autoclave were reduced to P1 and P2. P1 = 1.9-2.1 kg $/ \mathrm{cm}^{2}, \mathrm{P} 2=1.0-1.1 \mathrm{~kg} / \mathrm{cm}^{2}$ for A408-15 and A408-60; = 3.9-4.0 kg/cm², $2.0-2.1 \mathrm{~kg} / \mathrm{cm}^{2}$ for A428-15 and A428-60; $=3.5-4.0 \mathrm{~kg} / \mathrm{cm}^{2}, 2.0 \mathrm{~kg} / \mathrm{cm}^{2}$ for A438-15 and A438-60. 3: gas of GR in autoclave after opening the reactor lid at the end of autoclaving as the pressure in autoclave was reduced to ambient. 


\section{Conclusions}

This study conducted the pilot-scale autoclaving experiments of food wastes (FW) at various temperatures of 408,428 , and $438 \mathrm{~K}$ and times of 15 and $60 \mathrm{~min}$. The injected steam to the autoclave was supplied by the incineration plant with a gauge pressure of $7 \mathrm{~kg} / \mathrm{cm}^{2}$ and a temperature of $443 \mathrm{~K}$ or above. The results showed that the lower energy level and operation time by autoclaving were achieved at $408 \mathrm{~K}$ and $15 \mathrm{~min}$ (denoted as Case A408-15). The wet bulk density $\rho_{\mathrm{BW}}$ of $\mathrm{FW}_{\mathrm{A}}$ drastically increased from $359 \mathrm{~kg} / \mathrm{m}^{3}$ to $1031-1157 \mathrm{~kg} / \mathrm{m}^{3}(287.19 \%-322.28 \%$ relative to that of $\mathrm{FW})$ by autoclaving, while the volume reduction of FW decreased from $127.86 \mathrm{~L}$ down to 17.50-22.20 L. There was an increase of $\mathrm{C} / \mathrm{N}$ ratio of $\mathrm{FW}_{\mathrm{A}}$, while the contents of sulfur, hemi-cellulose, and cellulose of $\mathrm{FW}_{\mathrm{A}}$ decreased. These findings will be beneficial for subsequent processing and reutilization of $\mathrm{FW}_{\mathrm{A}}$ and other agricultural and livestock farming wastes with low $\mathrm{C} / \mathrm{N}$ ratios as compost.

The autoclaved liquid product (LA) separated from $\mathrm{FW}_{\mathrm{A}}$ and liquid condensate (LC) from the exit gas containing high electrical conductivity, COD, and TOC can be mixed to produce liquid fertilizer with suitable procedure. Moreover, the mixture of $\mathrm{FW}_{\mathrm{A}}, \mathrm{LA}$, and $\mathrm{LC}$ can be further treated by anaerobic digestion to provide biogas for power generation. These add to the appeal of sustainable materials management and the circular economy. The emitted gas from autoclaving contained non-detectable CO, while some hydrocarbons were identified by GC-MS. The results of this work will be useful for the design and cost-effectiveness assessment of the autoclaving pretreatment of food wastes from domestic households and food industries.

Author Contributions: C.-C.C., C.-Y.C., Y.-S.L. (Yuan-Shen Li), J.-L.S., and Y.-H.C. (Yi-Hung Chen) conceived and designed the experiments; Y.-S.L. (Yi-Shiou Lin), Z.-S.H., and Y.-C.W. performed the experiments; C.-C.C., C.-Y.C., Y.-S.L. (Yuan-Shen Li), J.-L.S., and Y.-H.C. (Yi-Hung Chen) analyzed the data; C.-Y.C., Y.-S.L. (Yuan-Shen Li), J.-L.S., Y.-H.C. (Yi-Hung Chen), C.-H.K., and F.-C.L. contributed reagents/materials/analysis tools; M.-H.Y., C.H., B.-L.L., K.-W.L., and S.-G.W. discussed the results and provided suggestion; C.-C.C., Y.-H.C. (Yen-Hau Chen), and C.-Y.C. wrote the paper; C.-C.C., Y.-H.C. (Yen-Hau Chen), C.-Y.C., and M.-H.Y. revised the paper.

Acknowledgments: The authors are grateful for the financial supports of this research provided by the Ministry of Science and Technology of Taiwan.

Conflicts of Interest: The authors declare no conflict of interest.

\section{Nomenclature}

\begin{tabular}{|c|c|}
\hline AT-t & Autoclaving at $\mathrm{T} \mathrm{K}$ and $\mathrm{t} \min$ (e.g., A408-15: at $408 \mathrm{~K}$ and $15 \mathrm{~min}$ ) \\
\hline CG1, CG2 & concentrations of G1, G2 (ppmv) \\
\hline CGR & Concentrations of GR (ppmv) \\
\hline COD & Chemical oxygen demand (mg/L) \\
\hline EC & Electrical conductivity $(\mu \mathrm{S} / \mathrm{cm})$ \\
\hline G1, G2 & $\begin{array}{l}\text { Released gases after condenser as pressures in autoclave were reduced to P1 and P2 after } \\
\text { finishing the autoclaving at setting time }\end{array}$ \\
\hline GR & $\begin{array}{l}\text { Gas in autoclave after opening the reactor lid at the end of autoclaving as the pressure in } \\
\text { autoclave was reduced to ambient }\end{array}$ \\
\hline $\mathrm{H}_{\mathrm{HDM}}$ & Higher heating value per mass in dry basis $(\mathrm{kcal} / \mathrm{kg})$ \\
\hline $\mathrm{H}_{\mathrm{HDV}}$ & Higher heating value per volume in dry basis $(\mathrm{kcal} / \mathrm{kg})$ \\
\hline $\mathrm{H}_{\mathrm{HWM}}$ & Higher heating value per mass in wet basis $(\mathrm{kcal} / \mathrm{kg})$ \\
\hline $\mathrm{M}_{\mathrm{A}}$ & Ash (wt.\%) \\
\hline $\mathrm{M}_{\mathrm{C}}$ & Combustibles (wt.\%) \\
\hline $\mathrm{M}_{\mathrm{FC}}$ & Fixed carbon (wt.\%) \\
\hline $\mathrm{M}_{\mathrm{VM}}$ & Volatile matters (wt.\%) \\
\hline $\mathrm{M}_{\mathrm{W}}$ & Water content (wt.\%) \\
\hline $\mathrm{NH}_{3}-\mathrm{N}$ & ammonium nitrogen $(\mathrm{mg} / \mathrm{L})$ \\
\hline $\mathrm{P}$ & Steam pressure for autoclaving $\left(\mathrm{kg} / \mathrm{cm}^{2}\right.$, gauge $)$ \\
\hline
\end{tabular}




$\begin{array}{ll}\mathrm{P} 1, \mathrm{P} 2 & \text { Two pressures in autoclave as gas w } \\ \mathrm{r} & \text { time }\left(\mathrm{kg} / \mathrm{cm}^{2}, \text { gauge }\right) \\ \mathrm{T} & \text { Rotation speed of autoclave }(\mathrm{rpm}) \\ \mathrm{THCs} & \text { Autoclaving temperature }\left(\mathrm{K} \text { or }{ }^{\circ} \mathrm{C}\right) \\ \mathrm{TOC} & \text { Total hydrocarbons }(\mathrm{ppmv}) \\ \mathrm{t} & \text { Total organic carbons }(\mathrm{mg} / \mathrm{L}) \\ \mathrm{V}_{\mathrm{BW}} & \text { Autoclaving times }(\mathrm{min}) \\ \rho_{\mathrm{BD}} & \text { Wet bulk volume }(\mathrm{L}) \\ \rho_{\mathrm{BW}} & \text { Dry bulk density }\left(\mathrm{kg} / \mathrm{m}^{3}\right) \\ & \text { Wet bulk density }\left(\mathrm{kg} / \mathrm{m}^{3}\right)\end{array}$

\section{Abbreviations}

$\begin{array}{ll}\text { ASTM } & \text { American Society for Testing and Materials } \\ \text { CNS } & \text { Chinese National Standards } \\ \text { FW } & \text { Food wastes } \\ \text { FW }_{\text {A }} & \text { Autoclaved food wastes } \\ \text { LC } & \text { Condensed liquid from the released gas from autoclave } \\ \text { LA } & \text { Autoclaved liquid product separated from FW } \\ \text { HTL } & \text { Hydrothermal liquefaction } \\ \text { IWPB } & \text { Initiative Wood Pellet Buyers } \\ \text { MSW } & \text { Municipal solid wastes } \\ \text { NIEA } & \text { National Institute of Environmental Analysis } \\ \text { RDF } & \text { Refused derived fuel } \\ \text { SRF } & \text { Solid recovered fuel } \\ \text { TBSMI } & \text { Taiwan Bureau of Standards, Metrology, and Inspection }\end{array}$

\section{References}

1. Chang, C.Y.; Li, Y.S.; Shie, J.L.; Chen, Y.H.; Chang, C.C. The Evaluation of Autoclaving Process for Municipal Solid Waste Separation; Report No. EPA-98-1605-02-02; Environmental Protection Agency: Washington, DC, USA, 2010. (In Chinese)

2. Eley, M.H.; Holloway, C.C. Treatment of municipal solid wastes by steam classifi-cation for recycling and biomass utilization. Appl. Biochem. Biotechnol. 1988, 17, 125-135. [CrossRef]

3. Eley, M.H. An improved prototype apparatus and process for separating cellu-losic materials from municipal solid waste. Appl. Biochem. Biotechnol. 1994, 45-46, 69-79. [CrossRef]

4. Environments Consulting Ltd.; Department for Environment, Food and Rural Affairs (Defra). Mechanical heat Treatment of Municipal Solid Waste; Environments Consulting Ltd.: Cambourne, UK, 2007. Available online: http:/ / www.defra.gov.uk/environment/waste/residual/newtech/docu-ments/mht.pdf (accessed on 22 August 2018).

5. Environments Consulting Ltd.; Department for Environment, Food and Rural Affairs (Defra). Introductory Guide to Options for the Diversion of Biodegradable Municipal Waste from Landfill; Environments Consulting Ltd.: Cambourne, UK, 2007. Available online: http:/ /www.defra.go-v.uk/environment/waste/residual/ newtech/documents/introductory-guide-2007.pdf (accessed on 22 August 2018).

6. Garg, A.; Smith, R.; Hill, D.; Simms, N.; Pollard, S. Wastes as co-fuels: The policy framework for solid recovered fuel (SRF) in Europe, with UK implications. Environ. Sci. Technol. 2007, 41, 4868-4874. [CrossRef] [PubMed]

7. Holloway, C.C.; Holloway, L.B. Process for Separating and Recovering Organics and Inorganics from Waste Material. U.S. Patent 4,342,830, 3 August 1982.

8. Hung, Z.S.; Chang, C.C.; Ho Chang, C.F.; Wang, Y.C.; Chang, C.Y.; Ji, D.R. Autoclaving of waste plastics-free papers for the resource recovery and reutilization. Fresen. Environ. Bull. 2012, 21, 2486-2493.

9. Hung, Z.S.; Chang, C.C.; Ho Chang, C.F.; Lin, Y.S.; Ji, D.R.; Chang, C.Y.; Tseng, J.Y.; Chiang, S.W.; Shie, J.L.; Chen, Y.H.; Ko, C.H.; Li, Y.S. Autoclaving treatment of wasted disposable bamboo chopsticks. J. Taiwan Inst. Chem. Eng. 2013, 44, 1010-1015. [CrossRef] 
10. Papageorgiou, A.; Barton, J.R.; Karagiannidis, A. Assessment of the greenhouse effect impact of technologies used for energy recovery from municipal waste: A case for England. J. Environ. Manag. 2009, 90, 2999-3012. [CrossRef] [PubMed]

11. Chang, C.Y.; Li, Y.S.; Wu, C.H.; Shie, J.L.; Chen, Y.H.; Lin, F.C. Low-temperature Biomass Pyrolysis Test Facility System Construction for the Solid Alternative Biofuel Production; Report No. EPA- 99-1605-02-03; Environmental Protection Agency: Washington, DC, USA, 2010. (In Chinese)

12. Chen, Y.H.; Chang, C.C.; Chang, C.Y.; Yuan, M.H.; Ji, D.R.; Shie, J.L.; Lee, C.H.; Chen, Y.H.; Chang, W.R.; Yang, T.Z.; et al. Production of a Solid Bio-fuel from Waste Bamboo Chopsticks by Torrefaction for Cofiring with Coal. J. Anal. Appl. Pyrol. 2017, 126, 315-322. [CrossRef]

13. Chang, C.C.; Chen, C.P.; Yang, C.S.; Chen, Y.H.; Huang, M.; Chang, C.Y.; Shie, J.L.; Yuan, M.H.; Chen, Y.H.; Ho, C.; et al. Conversion of waste bamboo chopsticks to bio-oil via catalytic hydrothermal liquefaction using K2CO3. Sustain. Environ. Res. 2016, 26, 262-267. [CrossRef]

14. Gao, W.; Chen, Y.; Zhan, L.; Bian, X. Engineering properties for high kitchen waste content municipal solid waste. J. Rock Mechan. Geotech. Eng. 2015, 7, 646-658. [CrossRef]

15. TEPA. Properties of Municipal Solid Waste in Environment Statistics. Environmental Protection Administration of Taiwan (TEPA): Taiwan. Available online: http:/ /www.epa.gov.tw/en/statistics/c4020. pdf (accessed on 17 August 2018).

16. Russ, W. Food waste as a renewable energy source. Thermoteiinika 2006, 1-2, 66-73.

17. Sun, Y.; Cheng, J. Hydrolysis of lignocellulosic materials for ethanol production: A review. Bioresour. Technol. 2002, 83, 1-11.

18. IWPB Initiative Wood Pellet Buyers (IWPB). IEE Pellcert Europe (2012-2014): Standardizing Wood Pellets Trading in Europe. Available online: http://www.laborelec.be/ENG/services/biomass-analysis/.woodpellet-standards/ (accessed on 22 August 2018).

19. TTIA. Irrigate Water Quality Standards, Taitung Irrigation Association (TTIA), Taiwan. Available online: http:/ / www.ttia.gov.tw / page8-5.php (accessed on 22 August 2018).

20. Bougrier, C.; Albasi, C.; Delgenes, J.P.; Carrère, H. Effect of ultrasonic, thermal and ozone pre-treatments on waste activated sludge solubilisation and anaerobic digestion biodegradability. Chem. Eng. Process. 2006, 45, 711-718. [CrossRef]

21. Le, T.M.; Vo, P.T.; Tran, L.T.; Truong, H.T.; Le, T.T.X.; Nguyen, T.M.; Do, M.V.; Chang, C.C.; Chen, Y.H.; Chang, C.Y. Effect of assisted ultrasonication and ozone pre-treatments on sludge characteristics and yield of biogas production with waste sludge from fishery wastewater treatment plant. 2018; in press. 